\title{
De-escalation in mental health care: a review of non-physical conflict management techniques
} Dirk Richter

\author{
Address: Westphalian Hospital Muenster, PO Box 202 252, D-48103 Muenster, Germany \\ from WPA Thematic Conference. Coercive Treatment in Psychiatry: A Comprehensive Review \\ Dresden, Germany. 6-8 June 2007 \\ Published: 19 December 2007 \\ BMC Psychiatry 2007, 7(Suppl I):SI46 doi:I0.1 186/147|-244X-7-SI-SI46
}

This abstract is available from: http://www.biomedcentral.com/I47I-244X/7/SI/SI 46

(c) 2007 Richter; licensee BioMed Central Ltd.

Until present, conflict management in mental health care relies much on physical techniques. Not surprisingly, research literature on interpersonal de-escalation in medical sciences, social sciences and psychology is rare. This presentation reviews rules and techniques that are applicable to mental health care [1]. Based on empirical data and theoretical models on the emergence of violence in psychiatry, following issues are discussed in detail: stress and anger management of staff, basic de-escalation rules, body language, facial expressions, verbal interventions. It is concluded that de-escalation in mental health care is still in its beginnings.

\section{References}

I. Richter D: Non-physical conflict management and de-escalation. In Violence in Mental Health Settings: Causes, Consequences, Management Edited by: Richter D, Whittington D. New York: Springer; 2006:125-144. 